Research Article

\title{
Relationship between $X P D, R A D 51$, and APEX1 DNA repair genotypes and prostate cancer risk in the male population of Rio de Janeiro, Brazil
}

\author{
Ana Sheila Cypriano $^{1 *}$, Gilda Alves ${ }^{2,7 *}$, Antonio Augusto Ornellas ${ }^{2,3}$, José Scheinkman ${ }^{4}$, Renata Almeida ${ }^{5}$, \\ Luciano Scherrer ${ }^{6}$ and Claudia Lage ${ }^{1}$ \\ ${ }^{1}$ Instituto de Biofisica Carlos Chagas Filho, Universidade Federal de Rio de Janeiro (UFRJ), Rio de \\ Janeiro, RJ, Brazil \\ ${ }^{2}$ Instituto Nacional de Câncer, Hospital do Câncer I, Rio de Janeiro, RJ, Brazil \\ ${ }^{3}$ Hospital Mário Kroeff, Rio de Janeiro, RJ, Brazil \\ ${ }^{4}$ Hospital Universitário Antônio Pedro, Niteroi, RJ, Brazil \\ ${ }^{5}$ Fundação Oswaldo Cruz, Rio de Janeiro, RJ, Brazil \\ ${ }^{6}$ Faculdades Kennedy, Belo Horizonte, MG, Brazil \\ ${ }^{7}$ Laboratório de Marcadores Circulantes, Departamento de Patologia, Faculdade de Ciências Médicas, \\ Universidade do Estado do Rio de Janeiro, Rio de Janeiro, RJ, Brazil
}

\begin{abstract}
Susceptibility to cancer ensues in individuals carrying malfunctioning DNA repair mechanisms. The impact of Single Nucleotide Polymorphisms (SNPs) in key DNA repair mechanisms on risk for prostate cancer was investigated in this case-control study. Samples consisted of 110 patients with confirmed prostate cancer and 200 unaffected men, from Rio de Janeiro, Brazil. XPD/Lys751Gln (rs13181), APEX1/Asp148Glu (rs1130409), and RAD51/G135C (rs1801320) SNPs were analyzed by PCR-RFLP. Allelic and genotypic frequencies were calculated and compared by Chi-Square test. The association between SNPs and clinical/epidemiological data was considered significant by Odds Ratio analysis, with IC95\% and a $p$-value $\leq 0.05$. Only the XPD/Lys751GIn SNP significantly increased susceptibility to disease in southeastern Brazilian men, with $p \leq 0.001$ [OR=2.36 (1.46-3.84)], with no association with $A P E X 1$ or RAD51 SNPs. Combined XPD+RAD51 SNPs were highly associated with the disease, $p \leq 0.005[\mathrm{OR}=3.40$ (1.32-9.20)]. A Chi-Square significant association between $X P D / L y s 751 \mathrm{Gln}$ and Gleason score was also observed (OR=9.31; IC95\%=1.19-428.0; $p=0.022$ ). Epidemiological inquiries revealed that exposure to pesticides significantly impacted the risk for prostate cancer in this population. DNA repair dysfunctions seem to prevail among workers exposed to chemical byproducts to cancer in this specific tissue. Non-invasive genotyping SNPs may help assessment of prostate cancer risk in environmentally exposed populations.
\end{abstract}

Keywords: Prostate cancer, single nucleotide polymorphism, XPD, DNA repair, gene-environment interaction.

Received: Fevereiro 20, 2017; Accepted: Julho 24, 2017.

\section{Introduction}

An increasing incidence of prostate cancer $(\mathrm{PCa})$ has been observed in Brazil, associated with longer lifetimes and due to improved diagnosis methods in countrywide information databases. The Brazilian National Cancer Institute (INCA) estimates approximately 61,200 new cases in 2016, with a risk of 61.82 cases per 100,000 men (INCA, 2016). Factors such as hypertension, smoking, alcohol consumption, sedentarism/obesity, hypercholesterolemia, and

Send correspondence to Claudia Lage. Laboratório de Radiações em Biologia, Carlos Chagas Filho Institute of Biophysics, CCS Bldg G, Federal University of Rio de Janeiro (UFRJ) 21941-902 Rio de Janeiro, RJ, Brazil. E- mail: lage @ biof.ufr..br

* both authors contributed equally for this study genetic history were identified as top risk factors for $\mathrm{PCa}$ (Bostwick et al., 2004).

Oxidative stress seems to influence the prostatic carcinogenic process because of its expressive association with aging and accumulating damage (Platz and Giovannucci, 2006). Likewise, environmentally-borne carcinogenic agents can also damage DNA, and different DNA repair mechanisms have been implicated in alleviating such harmful damages (Pramanik et al., 2011). Single Nucleotide Polymorphisms (SNPs) result from single-nucleotide changes in these genes, influencing expression or function of the affected genes. These changes could be critical concerning DNA repair functions.

The XPD (Xeroderma pigmentosum complementation group $D$ ) gene encodes one of the pro- 
teins involved in the Nucleotide Excision Repair (NER) pathway (O'Donovan and Wood, 1993). One of XPD's important SNPs is $X P D /$ Lys751Gln (rs13181), in which an A $\rightarrow$ C base substitution at exon 23 causes a Lys $\rightarrow$ Gln substitution in codon 751 , compromising part of the $\mathrm{C}$-terminal domain of the XPD protein and its full DNA repair capacity (White, 2009).

The APE1 endonuclease removes abasic sites from DNA, and is the top enzyme initiating recognition of damaged sites in human Base Excision Repair (BER), along with its 3' $\rightarrow 5$ ' exonuclease, DNA 3'-repair diesterase and DNA 3'-phosphatase activities. APE1 plays a major 3'phosphodiesterase role in initiating the repair of oxidative-generated single-strand breaks (Ramana et al., 1998). A missense $\mathrm{G} \rightarrow \mathrm{T}$ substitution SNP in the APEX1 gene in exon 5 (rs1130409) changes a critical Asp $\rightarrow$ Glu residue at codon 148. An up to date report connects this SNP to the development of $\mathrm{PCa}$ in Asian descendents (Chen et al., 2016).

The human RAD51 gene codes for a bacterial RecA recombinase homolog, central to the Homologous Recombination Repair (HRR) mechanism (Galkin et al., 2006). The RAD51 protein is critical for maintaining genomic integrity by repairing DNA double-strand breaks. The RAD51 polymorphism (rs1801320) implies in a $\mathrm{G} \rightarrow \mathrm{C}$ substitution mapping upstream the 5 ' untranslated promoter region at $-135 \mathrm{bp}$ from the transcription start. Although the functional consequences of this SNP remain to be clarified, a single nucleotide change in this $\mathrm{CpG}$ promoter island may up-regulate gene expression, thus affecting RAD51 mRNA levels (Antoniou et al., 2007). This SNP has been linked to breast and ovarian cancer susceptibility due to the supposed interaction of RAD51 with BRCA1 and BRCA2 proteins, with an especially higher risk for carriers of BRCA2 mutations (Levy-Lahad et al., 2001).

The investigation on this assembly of SNPs was designed because they significantly impact main DNA repair mechanisms (NER, BER and HRR, respectively) and genetic instability and, under this perspective, had never been addressed in a Brazilian population before. Considering the importance of DNA repair failures in cancer development, the aim of this work was to investigate the contribution of SNPs in key genes XPD/Lys751Gln, APEX1/Asp148Glu and $R A D 51 / \mathrm{G}-135 \mathrm{C}$ in the susceptibility to $\mathrm{PCa}$ in a case-control study in Rio de Janeiro, Brazil.

\section{Subjects and Methods}

\section{Study population}

For this study, 110 patients ( $62.0 \pm 6.5$ mean age at diagnostic) who had undergone radical prostatectomy and subsequent chemo- and/or radiotherapy were recruited between 2006-2008 from the National Cancer Institute (INCA) and Mario Kroeff Hospital (Rio de Janeiro, Brazil).
The control group consisted of 200 men $(61.6 \pm 10.3$ mean age) undergoing routine tests, without suspicion of $\mathrm{PCa}$, at the Antonio Pedro University Hospital (APUH, Niterói, RJ, Brazil), sampled between 2009-2010. The study was approved by the Ethics Committees of INCA (\#91/05) and APUH (\#48/09). All participants signed a written informed consent. The recruited patients carried T1, T2, or T3 prostate tumors, according to the TNM scoring system (tumor extension and metastasis).

Individuals included in the study met the clinical criteria of having a palpable mass by digital rectal examination (DRE) and/or elevated PSA serum levels $(C>2.5$ $\mathrm{ng} / \mathrm{mL}$ ) indicative of the occurrence of a tumor, followed by histopathological confirmation of $\mathrm{PCa}$. All patients were treated with radical prostatectomy. Gleason scoring was obtained by a pathologist's biopsy evaluation and PSA levels by clinical blood tests.

Patients and controls were interviewed following a structured individual questionnaire covering educational level, familial cancer and medical history, place and date of birth, place of birth of father and mother, weight, height, and place of residence. We also profiled the occurrence of prostate and other cancers in first-degree relatives, smoking status, and alcohol consumption. Patients and controls were asked to self-declare skin color, which is a normal question in such inquiries in Brazil. Controls and patients were excluded if they showed genetic syndromes and past cancer history.

\section{Genotyping}

Genomic DNA was isolated from 4-5 mL peripheral blood by proteinase $\mathrm{K}$ digestion and phenol-chloroform extraction (Sambrook, 1989). The selected SNPs were genotyped by polymerase chain reaction-restriction fragment length polymorphism (PCR-RFLP). The XPD/Lys751Gln (rs13181), RAD51/G-135C (rs1801320), and APEX1 Asp148Glu (rs1130409) SNPs were determined following conditions described by Baccarelli et al. (2004), Wang et al. (2001), and Hu et al. (2001), respectively.

$X P D$ and APEX1 amplicons were digested by $10 \mathrm{U}$ of the specific restriction endonucleases $\left(37^{\circ} \mathrm{C}, 2 \mathrm{~h}\right)$. The $X P D /$ Lys 751 Gln genotypes $\mathrm{A} / \mathrm{A}, \mathrm{A} / \mathrm{C}$, or $\mathrm{C} / \mathrm{C}$ were profiled as Pst I digestion products of 100/224, $66 / 100 / 158 / 224$, or $66 / 100 / 158$ bp bands, respectively. The APEX1/Asp148Glu genotypes T/T, T/G, or G/G were profiled as $B f a$ I digestion products of $164,164 / 144 / 20$, or $144 / 20$ bp bands, respectively. For RAD51/G-135C amplicons, digestions were performed with $10 \mathrm{U}$ of $B s t \mathrm{NI}\left(60^{\circ} \mathrm{C}\right.$, $1 \mathrm{~h}$ ). The genotypes $\mathrm{G} / \mathrm{G}, \mathrm{G} / \mathrm{C}$, or $\mathrm{C} / \mathrm{C}$ were profiled as digestion products of $71 / 87,71 / 87 / 157$, and $157 \mathrm{bp}$ bands, respectively. All samples were resolved on 3\% agarose gels and visualized by ethidium bromide staining. 


\section{Statistical analyses}

Genotypic frequencies between patient/control groups were analyzed by Chi-Square Test and Odds Ratios with $\mathrm{CI}=95 \%$. Contingency tables were used to compare groups concerning age, socio-economical and life style aspects by Chi-Square Test. Data were analyzed with Statistical Package 17.0 for Social Sciences (SPSS). Levels of significance $p \leq 0.05$, corresponding to $95.0 \%$ confidence, were considered in all analyses. All polymorphisms were regarded as potential markers by using the collective criteria of sensibility, specificity, positive and negative predictive values, and test accuracy.

\section{Results}

\section{Population profiling and clinical records}

Regarding age, there was no significant difference between patients $(62.0 \pm 6.5)$ and control groups (61.6 \pm 10.3$)$. Age-pairing between groups was essential concerning duration of exposure to environmental carcinogens. Case and control populations were also profiled similarly for basic items listed in Table S1 (geographic origin, education level, ethnic profile, familial cancer history, chronic diseases). When exposure to risk factors was weighted (tobacco, alcohol, or drug consumption), no significant differences were found between groups, with smokers and drinkers prevailing in both. Exposure to environmentally-borne agents (pesticides) was the only remarkable difference between case and control populations, and that caused a significant difference to appear $(p<0.0001)$ towards the patient's group. While $21.1 \%$ of patients declared having manipulated pesticides, only $3.5 \%$ of controls were subjected to this occupational hazard (Table $1)$.

Table 1 - Exposure to occupationally-borne and other risk factors between case and control groups.

\begin{tabular}{lccl}
\hline \multirow{2}{*}{ Risk Factors } & \multicolumn{2}{c}{ Groups } & \multirow{2}{*}{ p value } \\
\cline { 2 - 3 } & Controls, n (\%) & Cases, n (\%) & \\
\hline Organic solvents & $43(21.3)$ & $9(8.3)$ & \\
Chronic diseases & $91(45.7)$ & $45(41.3)$ & \\
Pesticides & $7(3.5)$ & $23(21.1)^{\mathrm{a}}$ & \\
Combustion products & $5(2.5)$ & $10(9.2)$ & $p<0.0001$ \\
Combustion + solvent & $3(1.5)$ & $1(0.9)$ & \\
None & $50(25.2)$ & $21(19.2)$ & \\
Totals & $199 *(100)$ & $109 *(100)$ & \\
\hline
\end{tabular}

Notes: p-value: descriptive level of the chi-square (Pearson). Only one $\mathrm{p}$-value refers to a statistical model that indistinguishably compares all variables listed between control and patients' groups.

${ }^{a}$ this particular environmental agent was highly significant $(p<0.05)$ in terms of risk for prostate cancer in exposed men.

*each patient was allocated in just one category, the one to which he declared to have been exposed to for longer periods.
The sampled populations were native to southeastern Brazil, mainly from the Rio de Janeiro metropolitan region $(80 \%)$. The majority self-declared as ethnically white (53.8\%), followed by brown or mulatto (30.7\%) and black (15.5\%). PSA values were obtained for 79 patients, ranging from $0.78-38.0 \mathrm{ng} / \mathrm{mL}$ (median $7.2 \pm 5.4 \mathrm{ng} / \mathrm{mL}$ ) (Table 2). Additional comparisons of SNP with age, prognosis, PSA level, and Gleason score unveiled two extra implications: (a) a Chi-Square significant association between XPD SNP and Gleason score $(\mathrm{OR}=9.31 ; 95 \% \mathrm{CI}=1.19-428.0$; $p=0.022$ ); (b) the RAD51 SNP related with unclear prognosis $(p=0.031)$.

\section{Prostate cancer risk and DNA repair genotyping}

Genotypes of $X P D, R A D 51$, and $A P E X 1$ were determined for 110 patients and 200 controls. The most common allele was considered as the reference one, whereas the less common ones were grouped as variants (risk polymorphism) (Table 3). Neither RAD51 (OR=1.13; 95\% $\mathrm{CI}=0.64-1.96)$ nor APEX1 polymorphic genes $(\mathrm{OR}=0.88 ; 95 \% \mathrm{CI}=0.55-1.42)$ were associated with risk for PCa. Only for XPD $(\mathrm{OR}=2.36 ; 95 \% \mathrm{CI}=1.46-3.84) \mathrm{a}$ positive association was found for variant $\mathrm{C} / \mathrm{C}$ or $\mathrm{A} / \mathrm{C}$ genotypes. Wild-type RAD51 patients were significantly ascribed as the poorer prognosis (Table 2).

Among the SNPs, the combined polymorphisms $X P D / R A D 51$ were found to have a harmful association $(\mathrm{OR}=3.40 ; 95 \% \mathrm{CI}=1.32-9.20 ; p \leq 0.05)$. Other combinations such as RAD51/APEX1 SNPs $\quad(\mathrm{OR}=0.86$; $95 \% \mathrm{CI}=0.28-2.60), \quad X P D / A P E X 1 \quad(\mathrm{OR}=2.30$; $95 \% \mathrm{CI}=0.76-8.08)$, or $X P D / R A D 51 / A P E X 1 \quad(\mathrm{OR}=1.43$; $95 \% \mathrm{CI}=0.34-5.07)$ resulted in non-significant risks for PCa (Table S2).

In a comparative analysis with the International HapMap database (www.hapmap.org), only the XPD polymorphic allele and genotypic frequencies were statistically different in relation to Chinese (CHB) and Japanese (JPT) populations, calculated by the Chi-Square test (Table S3).The variant allele frequency ranged from 0.076 for Japanese (JPT) to 0.358 for Native American Indians (GIH).

In order to estimate whether these polymorphic genes could fulfill the role of diagnostic/prognostic markers, we performed a data performance diagnostic test for available genotypes. As shown in Table 4, the combination $X P D / R A D 51$ SNPs scored better for sensitivity, specificity, and accuracy.

\section{Discussion}

The association between three dysfunctional SNPs (Asp148Glu/APEX1, G-135C/RAD51 and Lys751Gln $/ X P D$ ) and PCa susceptibility was evaluated in this case-control study. This is the first Brazilian study to cover SNPs in genes implicated in three main DNA repair pathways in a PCa population in Brazil. The present study 
Cypriano et al.

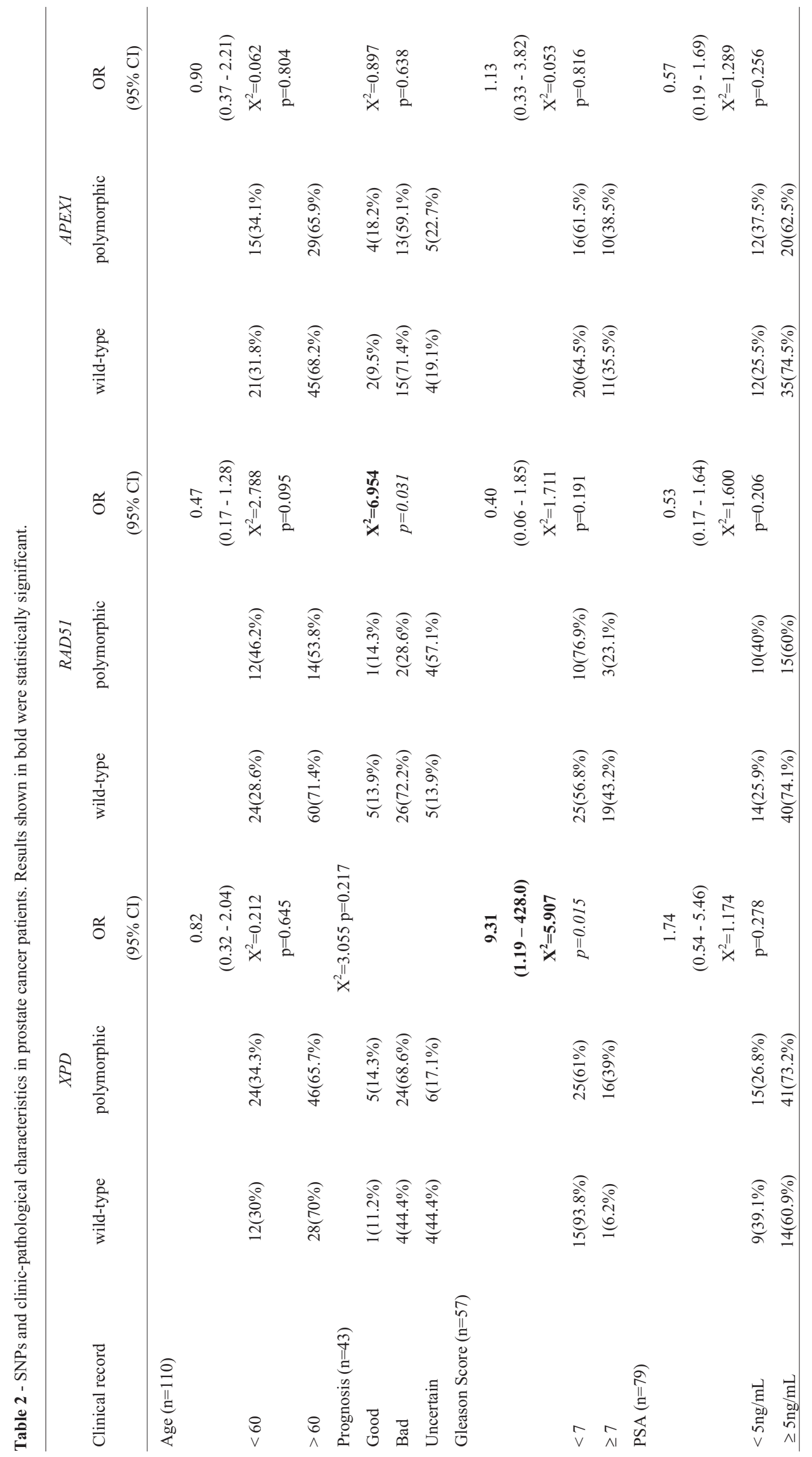


Table 3 - Genotypic frequencies of XPD, RAD51 and APEX1 genotypes in 110 prostate cancer patients and 200 controls. Results shown in bold were statistically significant.

\begin{tabular}{|c|c|c|c|c|c|c|c|c|c|c|}
\hline & \multicolumn{3}{|c|}{$X P D$} & \multicolumn{3}{|c|}{ RAD51 } & \multicolumn{3}{|c|}{$A P E X 1$} & \multirow[t]{2}{*}{ Totals } \\
\hline & $\mathrm{A} \mid \mathrm{A}$ & $\mathrm{A} \mid \mathrm{C}$ & $\mathrm{C} \mid \mathrm{C}$ & $\mathrm{G} \mid \mathrm{G}$ & $\mathrm{G} \mid \mathrm{C}$ & $\mathrm{C} \mid \mathrm{C}$ & $\mathrm{T} \mid \mathrm{T}$ & $\mathrm{T} \mid \mathrm{G}$ & $\mathrm{G} \mid \mathrm{G}$ & \\
\hline \multirow[t]{2}{*}{ Patients n (\%) } & $40(36.4)$ & $55(50.0)$ & $15(13.6)$ & $84(76.4)$ & $24(21.8)$ & $2(1.8)$ & $66(60.0)$ & $33(30.0)$ & $11(10.0)$ & 110 \\
\hline & & & & & & & & & & $(100)$ \\
\hline Control group n (\%) & $115(57.5)$ & $68(34.0)$ & $17(8.5)$ & $157(78.5)$ & $40(20.0)$ & $3(1.5)$ & $114(57.0)$ & $84(42.0)$ & $2(1.0)$ & $200(100)$ \\
\hline Totals & $155(50.0)$ & $123(39.7)$ & $32(10.3)$ & $241(77.7)$ & $64(20.6)$ & $5(1.6)$ & $180(58.1)$ & $117(37.7)$ & $13(4.2)$ & $310(100)$ \\
\hline \multirow[t]{2}{*}{ OR } & \multicolumn{3}{|c|}{2.36} & \multicolumn{3}{|c|}{1.13} & \multicolumn{3}{|c|}{0.88} & \\
\hline & \multicolumn{3}{|c|}{$(1.46-3.84)$} & \multicolumn{3}{|c|}{$(0.64-1.96)$} & \multicolumn{3}{|c|}{$(0.55-1.42)$} & \\
\hline$(95 \% \mathrm{CI})$ & \multicolumn{3}{|c|}{$p<0.001$} & \multicolumn{3}{|c|}{$p=0.766$} & \multicolumn{3}{|c|}{$p=0.696$} & \\
\hline Hardy-Weinberg Equilibrium & \multicolumn{3}{|c|}{$p=0.345$} & \multicolumn{3}{|c|}{$p=0.788$} & \multicolumn{3}{|c|}{$p=0.337$} & \\
\hline
\end{tabular}

$\mathrm{n}$ : number of individuals

Table 4 - Data performance diagnostic test calculated for each polymorphism alone and combined

\begin{tabular}{lcccc}
\hline Parameters & \multicolumn{4}{c}{ Probabilities } \\
\hline & XPD & RAD51 & APEX1 & $X P D+R A D 51$ \\
Sensitivity (\%) & $63.6(54.3-72.0)$ & $23.6(16.7-32.4)$ & $40.0(31.3-49.3)$ & $62.1(44.0-77.3)$ \\
Specificity (\%) & $57.5(50.5-64.1)$ & $78.5(72.3-83.6)$ & $57.0(50.0-63.7)$ & $68.0(54.2-79.2)$ \\
Positive predictive value (\%) & $45.2(37.5-53.0)$ & $37.7(27.2-49.5)$ & $33.8(26.3-42.3)$ & $52.9(36.7-68.5)$ \\
Negative predictive value (\%) & $74.2(66.7-80.4)$ & $65.1(58.9-70.8)$ & $63.3(56.1-70.0)$ & $75.6(61.3-85.7)$ \\
Accuracy (\%) & $59.7(54.1-65.0)$ & $59.0(53.5-64.3)$ & $50.1(45.4-56.5)$ & $65.8(54.8-75.3)$ \\
\hline
\end{tabular}

was, thus, designed to improve the genetic profiling of PCa patients by mapping a panel of DNA repair SNPs and assess its correlation with clinical parameters. A comparative epidemiological inquiry on known cancer risk factors was applied to cases and controls. The collected data revealed that exposure to environmental factors, as well as the XPD/Lys751Gln (rs13181) polymorphism appeared to be associated with increased risk for $\mathrm{PCa}$.

Major areas of research on PCa have focused on three main points: (1) assessment of how life style/environmental factors/diet can influence carcinogenesis; (2) strategies to delay disease onset and progression; and (3) finding accurate biomarkers to distinguish between indolent and aggressive forms (Shen and Abate-Shen, 2010). The present study was designed to target items (1) and (3).

\section{The roles of XPD and RAD51 SNPs in prostate cancer proneness}

A significantly increased risk for lymphohematopoietic, prostate, melanoma, and brain neoplasms has been surveyed among pesticide handlers and industry workers (Koutros et al., 2010). Moreover, the NER pathway was recently shown to repair damage induced by carcinogens, including pesticides (Barry et al., 2012). Accordingly, data from the present study associated an NER dysfunction $(X P D)$ with high risk for PCa (Table 3), especially in men exposed to pesticides. When risk factors were compared between cases and controls, a remarkable positive correlation was found only for exposure to pesticides. The expressive amount of XPD AC and CC polymorphic patients exposed to pesticides implies that they can steeply accumulate damages because of NER malfunction, leading to increased PCa risk.

Extensive DNA damage was detected in exposed floriculturists compared to non-exposed ones, and exposure to pesticides appeared as the primary genotoxic factor for long-term carcinogenesis (Bolognesi et al., 2004). Theophilou et al. (2015) followed-up transgenerational alterations in human prostate tissue samples over 30 years, correlated with geographic distribution and exposure to risk factors. Indeed, genotoxic agents seem to ensue longlasting genetic/epigenetic alterations, imprinting phenotypic pro-malignant changes.

Although the association of lifestyle and cancer risk had already been highlighted in a number of studies, none of the other noxious habits (smoking, drug use), or social aspects could be ascribed to PCa risk in the studied group. Here, only the XPD SNP was related to the risk of developing PCa. It is worthy of note that $X P D$-mediated NER corrects damages caused by environmental agents and reactive oxygen species (Mitra et al., 2001), these being important triggers of $\mathrm{PCa}$. This supports the complex genetic basis of $\mathrm{PCa}$ involving multiple susceptibility genes. 
Sulfolobus acidocaldarius XPD (SaXPD protein) harbors a catalytic site for its SaRAD51 protein, and all SaXPD helicase domains were conserved in human XPD (Fan and Wilson, 2005). Four domains comprise the SaXPD's catalytic core: two RAD51/RecA-like domains (HD1-HD2) and two additional HD1 domains inserted together. Twenty-two out of the known 26 point mutations related to XPD-linked human diseases mapped there (Xeroderma pigmentosum, Cockayne syndrome, and Trichothiodystrophy). Aloyz et al. (2002) showed that the physical association between human XPD and RAD51 proteins acting to remove DNA crosslinks maybe assembled in a larger complex. They appear to be recombination counterparts, modulating the HRR-mediated resistance to crosslinks.

By playing an important role in recovering damaged DNA in vertebrates, the RAD51 hyper-recombination phenotype can potentiate genomic instability (Klein, 2008). Schild and Wiese (2010) suggest that RAD51 overexpression can contribute to carcinogenic progression. Since XPD and RAD51 are counterparts in the repair of DNA breaks, their double malfunctions appeared statistically related to high risk for $\mathrm{PCa}$, perhaps because of the triggered genomic instability. Noteworthy, wild-type RAD51 patients underwent worse prognoses, probably because of better repair of therapy-induced DNA damages by HRR, while XPD/Lys751Gln patients displayed higher Gleason scores (Table 2). Despite the small number of cases analyzed, these correlations were highly significant.

Regarding general clinical findings, both specificity and sensitivity tests also revealed that $X P D$ and $X P D+R A D 51$ genotypes scored good negative predictive values (Table 4). Regarding the potential validity of our proposed panel, since $X P D$ and RAD51 SNPs significantly scored the top OR in a small population, they would probably reach a much more relevant status as risk markers when assessing a larger group.

A Spanish multicenter group revealed that genes involved in HRR could be associated with poor prognosis in PCa (Henriquez-Hernandez et al., 2014). Their findings corroborate ours, regarding the association of HRR SNPs with unclear prognosis. The same group reported that DNA repair genetic variants $(X R C C 6$ and $M V P$ ) were associated with more aggressive outcomes (Henriquez-Hernandez et al., 2016).

Our genetic analysis is endorsed by the HapMap database, i.e., the Southeast Brazilian population is quite different from the Japanese and Chinese. The European colonization remains strongly imprinted in Brazilian ethnicity, remaining genetically distant from Eastern populations. Accordingly, the genotypic profiling seen by HenriquezHernandez et al. (2014) in a Spanish population and a meta-analysis performed by Mi et al. (2012) with Asian and African populations matches our HapMap assessments.
Studies about ethnically-linked differences strengthen the need to continue research on new confident biomarkers.

\section{The APEX1 SNP counteracting risky genotypes}

Interestingly, the APEXI deficiency caused the risk for PCa to drop (Table S2), and this result is interpreted as deriving from the simultaneous knockdown of three key routes of DNA repair: HRR, NER, and BER. This probably drives prostatic cells to death, protecting the prostatic tissue from the outbreak of potentially malignant clones.

The APEX1/Asp148Glu (rs1130409) SNP was recorded in another Brazilian population (Kuasne et al., 2011), which appeared to be more susceptible to PCa. In our group, however, no susceptibility was connected with this SNP, maybe because of other genetic background differences between the sampled populations and the low penetrance of this SNP for cancer development.

\section{Genetic instability assessment and decision making in prostate cancer}

Data compiled for this Brazilian group revealed the need for a clinical follow-up, along with a panel of key DNA repair dysfunctions, instead of just one or two genes. Moreover, biomarker research has mainly targeted diagnosis, rather than prognosis and outcomes (Prensner et al., 2012), which are capable of tailoring individual therapeutics. For instance, Chantre-Justino et al. (2015) reported that patients with lower transcript levels of the APE1 gene belonged to the cohort with $100 \%$ lethality from aggressive bladder cancer. In prostate cancer, the expression of a panel of 17 genes belonging to nine different DNA damage and repair (DDR) pathways was determined in prostatectomy samples in a cohort study by Evans et al. (2016), where high expression of NER and BER genes significantly related to metastasis and lower overall survival. The authors envisaged the screening of individual "DDR signatures" to track aggressive prostate cancers on the basis of their differential response to therapy. These two studies on genetic markers in tumors of two urinary-related organs point out how tissue-specific the neoplastic process can be driven.

In this study, we observed that patients with a polymorphic XPD genotype significantly ranked at higher Gleason scores, indicating that NER-deficient individuals seem to bear genetically more instable tumors. In the absence of the error-free NER pathway, other concurrent error-prone mechanisms could take control of less accurately repair of DNA damages. In support of this finding, $X P D$ SNPs rs13181 and rs1799793 (XPD/Asp312Asn) tended to group under high Gleason scores and advanced tumor stages, although results were not statistically significant (Agalliu et al., 2010). Altogether, these findings help to unveil genetic features on how this disease is triggered and progresses in different populations, whose heterogeneity can render even more complex outcomes due to geneenvironment interactions. Present findings await corrobo- 
ration by other studies, focusing on environmental and ethnic factors impacting this important male cancer.

Complimentary tests, such as ultrasonography and biopsy should be included in more precise diagnostics, although the lower cutoff of $4.1 \mathrm{ng} / \mathrm{ml}$ of PSA protein, for example, is consensually taken as a good negative prediction (Van den Broeck et al., 2015). If early cancer detection by current tests is the desired target in cancer prevention, genotyping instability-prone DNA repair SNPs can be envisaged as the earliest informative test amongst all.

\section{Acknowledgments}

Financial support was provided by CAPES (Coordenação de Aperfeiçoamento de Pessoal de Nível Superior) and a fellowship to CL by Conselho Nacional de Desenvolvimento Científico e Tecnológico (CNPq). We also wish to acknowledge the assistance of Dr. Ana Hatagima (FioCruz, Brazil) during the initial development of this study.

\section{References}

Agalliu I, Kwon E, Salinas C, Koopmeiners JS, Ostrander EA and Stanford JL (2010) Genetic variation in DNA repair genes and prostate cancer risk: Results from a population-based study. Cancer Causes Control 21:289-300.

Aloyz R, Xu ZY, Bello V, Bergeron J, Han FY, Yan Y, Malapetsa A, Alaoui-Jamali M, Duncan A and Panasci L (2002) Regulation of cisplatin resistance and homologous recombinational repair by the TFIIH subunit XPD. Cancer Res 62:5457-5462.

Antoniou AC, Sinilnikova OM, Simard J, Léoné M, Dumont M, Neuhausen SL, Struewing JP, Stoppa-Lyonnet D, Barjhoux L, Hughes DJ, et al. (2007) RAD51 135G > C modifies breast cancer risk among BRCA2 mutation carriers: Results from a combined analysis of 19 studies. Am J Hum Genet 81:1186-1200.

Baccarelli A, Calista D, Minghetti P, Marinelli B, Albetti B, Tseng T, Hedayati M, Grossman L, Landi G, Struewing JP, et al. (2004) XPD gene polymorphism and host characteristics in the association with cutaneous malignant melanoma risk. Br J Cancer 90:497-502.

Barry KH, Koutros S, Andreotti G, Sandler DP, Burdette LA, Yeager M, Beane Freeman LE, Lubin JH, Ma X, Zheng T, et al. (2012) Genetic variation in nucleotide excision repair pathway genes, pesticide exposure and prostate cancer risk. J Carcinog 33:331-337.

Bolognesi C, Landini E, Perrone E and Roggieri P (2004) Cytogenetic biomonitoring of a floriculturist population in Italy: Micronucleus analysis by fluorescence in situ (FISH) with all-chromosome centromeric probe. Mutat Res 557:109117.

Bostwick DG, Burke HB, Djakiew D, Euling S, Ho SM, Landolph J, Morrison H, Sonawane B, Shifflett T, Waters DJ, et al. (2004) Human Prostate Cancer Risk Factors. J Am Cancer Soc 101:2371-2490.

Chantre-Justino M, Alves G, Britto C, Cardoso A, Scherrer L, Moreira Ados S, Quirino R, Ornellas A, Leitão A and Lage C (2015) Impact of reduced levels of APE1 transcripts on the survival of patients with urothelial carcinoma of the bladder). Oncol Rep 34:1667-1674.

Chen Y, Li J and Mo Z (2016) Association between the APEX1 Asp148Glu polymorphism and prostate cancer, especially among Asians: A new evidence-based analysis. Oncotarget 7:52530-52540.

Evans JR, Zhao SG, Chang SL, Tomlins SA, Erho N, Sboner A, Schiewer MJ, Spratt DE, Kothari V, Klein EA, et al. (2016) Patient-level DNA damage and repair pathway profiles and prognosis after prostatectomy for high-risk prostate cancer. JAMA Oncol 2:4710480.

Fan J and Wilson DM (2005) Protein-protein interactions and post translational modifications in mammalian base excision repair. Free Radic Biol Med 38:1121-1138.

Galkin VE, Wu Y, Zhang XP, Qian X, He Y, Yu X, Heyer WD, Luo Y and Egelman EH (2006) The Rad51/RadA N-terminal domain activates nucleoprotein filament ATPase activity. Structure 14:983-992.

Gangwar R, Manchanda PK and Mittal RD (2009) Implications of XRCC1, XPD and APE1 gene polymorphism in North Indian population: A comparative approach in different ethnic groups worldwide. Genetica 136:163-169.

Henríquez-Hernández LA, Valenciano A, Foro-Arnalot P, Álvarez-Cubero MJ, Cozar JM, Suárez-Novo JF, CastellsEsteve M, Fernández-Gonzalo P, De-Paula-Carranza B, Ferrer M, et al. (2014) Single nucleotide polymorphisms in DNA repair genes as risk factors associated to prostate cancer progression. BMC Med Genet 15:143.

Henríquez-Hernández LA, Valenciano A, Foro-Arnalot P, Álvarez-Cubero MJ, Cozar JM, Suárez-Novo JF, CastellsEsteve M, Fernández-Gonzalo P, De-Paula-Carranza B and Ferrer $\mathrm{M}$ et al. (2016) Association between singlenucleotide polymorphisms in DNA double-strand break repair genes and prostate cancer aggressiveness in the Spanish population. Prostate Cancer Prostat Dis 19:28-34.

$\mathrm{Hu}$ JJ, Smith TR, Miller MS, Mohrenweiser HW, Golden A and Case LD (2001) Amino acid substitution variants of APE1 and XRCC1 genes associated with ionizing radiation sensitivity. Carcinogenesis 22:917-922.

INCA, Brazilian National Cancer Institute (2016). Estimate 2015-2016. Cancer Incidence in Brazil. Rio de Janeiro: Brazil. Health Ministry. Department of Health Care. Brazilian National Cancer Institute. Prevention Coordination and Monitoring, Rio de Janeiro, RJ, Brazil.

Klein HL (2008) The consequences of Rad51 overexpression for normal and tumor cells. DNA Repair 7:686-693.

Koutros S, Alavanja M and Freeman L (2010) An update of cancer incidence in the agricultural health study. J Occup Environ Med 52:1098-1105.

Kuasne H, Rodrigues IS, Losi-Guembarovski R, Reis MB, Fuganti PE, Gregório EP, Libos Junior F, Matsuda HM, Rodrigues MA, Kishima MO, et al. (2011) Base excision repair genes XRCC1 and APEX1 and the risk for prostate cancer. Mol Biol Rep 38:1585-1591.

Levy-Lahad E, Lahad A, Eisenberg S, Dagan E, Paperna T, Kasinetz L, Catane R, Kaufman B, Beller U, Renbaum P, et al. (2001) A single nucleotide polymorphism in the RAD51 gene modifies cancer risk in BRCA2 but not BRCA1 carriers. Proc Natl Acad Sci USA 98:3232-3236.

Majumder M, Sikdar N, Ghosh S and Roy B (2007) Polymorphisms at XPD and XRCC1 DNA repair loci and increased 
risk of oral leukoplakia and cancer among NAT2 slow acetylators. Int J Cancer 120:2148-2156.

Mi Y, Zhang L, Feng N, Wu S, You X, Shao H, Dai F, Peng T, Qin $\mathrm{F}$, Zou J, et al. (2012) Impact of two common xeroderma pigmentosum group D (XPD) gene polymorphisms on risk of prostate cancer.PLoS One 7:e44756.

Mitra S, Boldogh I, Izumi T and Hazra TK (2001) Complexities of the DNA base excision repair pathway for repair of oxidative DNA damage. Environ Mol Mutagen 38:180-190.

O'Donovan A and Wood RD (1993) Identical defects in DNA repair in xeroderma pigmentosum group $\mathrm{G}$ and rodent ERCC group 5. Nature 363:185-188.

Platz EA and Giovannucci E (2006) Prostate cancer. In: Schottenfeld D, Fraumeni Jr JF (eds) Cancer Epidemiology Biomarkers \& Prevention. $3^{\text {rd }}$ edition. Oxford, pp 1128-1150.

Pramanik S, Devi S, Chowdhary S, Surendran ST, Krishnamurthi $\mathrm{K}$ and Chakrabarti T (2011) DNA repair gene polymorphisms at XRCC1, XRCC3, XPD and OGG1 loci in Maharashtrian population of central India. Chemosphere 82:941946.

Prensner J, Rubin M, Wei J and Cinnalyan AM (2012) Beyond PSA: The next generation of prostate cancer biomarkers. Sci Transl Med 4:127rv3.

Ramana CV, Boldogh I, Izumi T and Mitra S (1998) Activation of apurinic/apyrimidinic endonuclease in human cells by reactive oxygen species and its correlation with their adaptive response to genotoxicity of free radicals. Proc Natl Acad Sci USA 95:5061-5066.

Sambrook J (1989) Molecular Cloning: A Laboratory Manual. 2nd edition. Cold Spring Harbor Laboratory Press, New York, $1659 \mathrm{p}$.

Schild D and Wiese C (2010) Overexpression of RAD51 suppresses recombination defects: A possible mechanism to reverse genomic instability. Nucleic Acids Res 38:1061-1070.
Shen MM and Abate-Shen C (2010) Molecular genetics of prostate cancer: New prospects for old challenges. Genes Dev 24:1967-2000.

Theophilou G, Lima KM, Briggs M, Martin-Hirsch PL, Stringfellow HF and Martin FL (2015) A biospectroscopic analysis of human prostate tissue obtained from different time periods points to a trans-generational alteration in spectral phenotype. Sci Rep 5:13465.

Van den Broeck T, De Ridder D and Van der Aa F (2015) The value of surgical release after obstructive anti-incontinence surgery: An aid for clinical decision making. Neurourol Urodyn 34:736-740.

Vettriselvi V, Vijayalakshmi K, Solomon PF and Venkatachalam P (2007) XRCC1 and XPD gene polymorphisms in a South Indian population. Asian Pac J Cancer Prev 8:283-286.

Wang WW, Spurdle AB, Kolachana P, Bove B, Modan B, Ebbers SM, Suthers G, Tucker MA, Kaufman DJ, Doody MM, et al. (2001) A single nucleotide polymorphism in the 5' untranslated region of RAD51 risk of cancer among BRCA1/2 mutation carriers. Cancer Epidemiol Biomarkers Prev 10:421.

White M (2009) Structure, function and evolution of the XPD family of iron-sulfur containing $5^{\prime} \rightarrow 3^{\prime}$ DNA helicases. Biochem Soc Trans 37:547-551.

\section{Supplementary material}

The following online material is available for this article: Table S1 - Distribution of patients and controls among different socio-economical and life style groups.

Table S2 - Frequencies of the combined genotypes in 110 prostate cancer patients and 200 controls.

Table S3 - Allelic and genotype frequencies of XPD Lys751Gln in HapMap and Brazilian populations.

Associate Editor: Mara H. Hutz

License information: This is an open-access article distributed under the terms of the Creative Commons Attribution License (type CC-BY), which permits unrestricted use, distribution and reproduction in any medium, provided the original article is properly cited. 